University of Wollongong

Research Online

Faculty of Law, Humanities and the Arts Papers (Archive)

Faculty of Arts, Social Sciences \& Humanities

$1-1-2007$

The narrative practice hypothesis: origins and applications of folk psychology

Daniel Hutto

University of Wollongong

Follow this and additional works at: https://ro.uow.edu.au/lhapapers

Part of the Arts and Humanities Commons, and the Law Commons

Research Online is the open access institutional repository for the University of Wollongong. For further information contact the UOW Library: research-pubs@uow.edu.au 


\title{
The narrative practice hypothesis: origins and applications of folk psychology
}

\author{
Abstract \\ Psychologically normal adult humans make sense of intentional actions by trying to decide for which \\ reason they were performed. This is a datum that requires our understanding. Although there have been \\ interesting recent debates about how we should understand 'reasons', I will follow a long tradition and \\ assume that, at a bare minimum, to act for a reason involves having appropriately interrelated beliefs and \\ desires.

\section{Keywords} \\ narrative, practice, hypothesis, applications, origins, psychology, folk \\ Disciplines \\ Arts and Humanities I Law \\ Publication Details \\ Hutto, D. (2007). The narrative practice hypothesis: origins and applications of folk psychology. \\ Philosophy, 60 (May), 43-68.
}


Royal Institute of Philosophy Supplement

http://journals.cambridge.org/PHS

Additional services for Royal Institute of Philosophy Supplement:

Email alerts: $\underline{\text { Click here }}$

Subscriptions: $\underline{\text { Click here }}$

Commercial reprints: $\underline{\text { Click here }}$

Terms of use : $\underline{\text { Click here }}$

\section{The Narrative Practice Hypothesis: Origins and Applications of Folk Psychology}

Daniel D. Hutto

Royal Institute of Philosophy Supplement / Volume 60 / May 2007, pp 43 - 68

DOI: 10.1017/S1358246107000033, Published online: 09 August 2007

Link to this article: http://journals.cambridge.org/abstract_S1358246107000033

How to cite this article:

Daniel D. Hutto (2007). The Narrative Practice Hypothesis: Origins and Applications of Folk Psychology. Royal Institute of Philosophy Supplement, 60, pp 43-68 doi:10.1017/S1358246107000033

Request Permissions : $\underline{\text { Click here }}$ 


\title{
The Narrative Practice Hypothesis: Origins and Applications of Folk Psychology
}

\author{
DANIEL D. HUTTO
}

\section{Folk Psychological Practice}

Psychologically normal adult humans make sense of intentional actions by trying to decide for which reason they were performed. This is a datum that requires our understanding. Although there have been interesting recent debates about how we should understand 'reasons', I will follow a long tradition and assume that, at a bare minimum, to act for a reason involves having appropriately interrelated beliefs and desires.

He left the party because he believed the host had insulted him. She will head for the cabin in the woods because she wants peace and quiet. These are typical examples of reason explanations, one backward looking and the other future facing. Both imply more than they say. To leave a party because of a suspected insult suggests that one desires not to be insulted, or at least it implies that the desire to avoid insult is stronger than that for some other good on offer. Similarly, to seek tranquillity in an isolated cabin implies that one believes that it can be found there, or at least more so than elsewhere. Despite the fact that the situations and characters involved in these dramas are woefully under-described, we are able to 'make sense' of these actions in a basic manner using the belief/desire schema. This involves designating a particular pairing of a belief and a desire, each with its own specified propositional content, in a way that rests on a quiet understanding of the way propositional attitudes inter-relate.

To understand which beliefs and desires were responsible for a person's action is normally only to understand why they acted in a quite skeletal way. Maximally, to understand why someone acted requires a more or less detailed description of his or her circumstances, other propositional attitudes (hopes, fears), more basic perceptions and emotions and perhaps even his or her character, current situation and history. In short, to fully grasp why someone took action on a particular occasion requires relating that 


\section{Daniel D. Hutto}

person's 'story'. While I think this richer understanding of what it is to act for reasons is important, my primary interest is to better understand how we acquire and apply our understanding of 'folk psychology' more minimally construed. ${ }^{1}{ }^{\mathrm{I}}$ am interested in how we become skilled at the practice of predicting, explaining and explicating actions by appeal to reasons of the sort that minimally have belief/desire pairings at their core. To keep things straight, let us call this folk psychology stricto sensu.

It is a commonplace in Anglophone philosophy that adult humans make regular and reliable use of 'folk pyschology', so understood. Some maintain this fuels even our most basic encounters with others in daily life and that a great many of our social institutions depend upon it. In promoting these ideas, many so-called friends of folk psychology have overstated and misunderstood its role in social cognition and our lives more generally. First, they typically see it as more basic and far more pervasive than it is. We have many other-more basic, both phylogenetically and ontogenetically-means of conducting social coordinations, interactions and engagements. These yield neither predictions nor explanations per se but instead involve recognition-response patterns that generate 'embodied expectations'. In 'normal' contexts these are not only quicker but also far more powerful and reliable ways of relating to others and navigating social dynamics. ${ }^{2}$ It is therefore false to say that without a capacity for folk psychology we would be bereft of any reliable means of interacting

1 Some prefer to talk of 'commonsense psychology' as opposed to 'folk psychology', because the latter label was pejoratively fashioned by the enemies of this practice in order to highlight its weak scientific credentials. Calling it 'folk' psychology was meant to signal that its tenets are outmoded, limited and backward-i.e. to highlight the fact that it is indeed 'folksy'. However, since I do not think this folk practice can be usefully compared with the promises of a scientific psychology, I am happy to defend the vulgar on this (see D. D. Hutto, The Presence of Mind (Amsterdam: John Benjamins, 1999)).

2 See D. D. Hutto, 'The Limits of Spectatorial Folk Psychology', Mind and Language 19, 2004, 548-73; D. D. Hutto, 'Unprincipled Engagements: Emotional Experience, Expression and Response', Radical Enactivism: Focus on the Philosophy of Daniel D. Hutto, R. Menary (ed.) (Amsterdam/Philadelphia: John Benjamins, 2006). See also H. De Jaegher, Social Interaction Rhythm and Participatory Sense-Making: An Embodied, Interactional Approach to Social Understanding, with Some Implications for Autism (Brighton, University of Sussex, 2006), unpublished DPhil thesis. 


\section{The Narrative Practice Hypothesis}

with others. Nor do we call on it that often. ${ }^{3}$ Many of our routine encounters with others take place in situations in which the social roles and rules are well established, so much so that unless we behave in a deviant manner we typically have no need to understand one another by means of the belief/desire schema. ${ }^{4}$ More often than not we neither predict nor seek to explain the actions of others in terms of their unique beliefs and desires at all.

That said, sometimes the actions of others cry out for explanation-sometimes they violate norms (or appear to do so) in ways that we can only make sense of by understanding them in a wider context; by acquiring the narrative that fills in or fleshes out the particular details of that person's story. Any account that has as its subject matter the reason why a person acted on a particular occasion (as restrictively defined above) I will call a folk psychological narrative. ${ }^{5}$ The practice of supplying such narratives just is that of explicating and explaining action in terms of reasons-the application of the belief/desire framework. Folk psychology is thus, in essence, a peculiar kind of narrative practice.

Folk psychological narratives come in both third-personal and second-personal varieties. This is important since the success or otherwise of such explanations depends mainly on who is doing the telling-i.e. who produces the account. Although we often attempt to generate such accounts on behalf of others, even when this speculative activity is well supported-say, by simulative or theoretical heuristics-it is quite unlikely that such attempts will

3 S. Gallagher, 'The Practice of Mind: Theory, Simulation or Primary Interaction?' Fournal of Consciousness Studies 8, No. 5-7, 2001, 83-108.

4 J. Bruner, Acts of Meaning (Cambridge, MA: Harvard University Press, 1990); J. Bermúdez, 'The Domain of Folk Psychology', Minds and Persons, A. O’Hear (ed.) (Cambridge: Cambridge University Press, 2003).

5 We might also call these 'people-narratives'; for they are 'narratives in which people feature as people (and not, for example, as objects for scientific investigation), the narrative should also present what happened in a way that enables the audience or the reader to make sense of the thoughts, feelings, and actions of those people who are internal to the narrative' (P. Goldie, On Personality (London: Routledge, 2004), 115). For expositional variety, I use these terms interchangeably. Of course, this presupposes the uncontentious idea that there are different types of narratives and that these can be classified by their content and subject matter. 


\section{Daniel D. Hutto}

succeed in hitting on the 'right' explanation. Indeed, it seems that the likelihood of success is more or less inversely proportional to need. ${ }^{6}$

Although hardly foolproof, by far the best and most reliable means of obtaining a true understanding of why another has acted is to get the relevant story directly from the horse's mouth. The activity is familiar enough. Such accounts are typically deliveredindeed, fashioned-in the course of ordinary dialogue and conversation. It is because of this that they are usually sensitive to a questioner's precise explanatory needs and requirements. The nature of such engagements is complex and deserves greater attention than it has received to date, but that is not my focus here. So far, all I want to draw attention to is the banal truism that second-person deliveries of these folk psychological narratives do much of the heavy lifting in enabling us to make sense of the actions of others in daily life-i.e. when there is a need to do so.

While I suspect that we may use folk psychology far less frequently and less reliably than is generally supposed by its friends, folk psychological practice is important and our capacity to engage in it warrants explanation. The above observations, however, should immediately raise doubts about the credibility of the favoured hypotheses about its ultimate origins. Orthodoxy has it that our 'theory of mind' abilities are the consequence of the hard work of subpersonal mechanisms. And, although there is much debate about the precise character of the latter, these devices are typically thought to be a kind of native cognitive endowment, gifted to us by our evolutionary forefathers.

In light of the above and on close scrutiny, it seems quite unlikely that this ability was the ancient solution to an adaptive problem that arose for our ancestors during the Pleistocene epoch, enabling 'the rapid comprehension and prediction of another organism's behaviour'. ${ }^{7}$ Third-personal mindreading involving the attribution of interlaced propositional attitudes would have been unnecessary for oiling our primary forms of social interaction and even for sophisticated activities such as lexicon formation and language

see Hutto, 2004, op. cit. note 4.

S. Baron-Cohen, Mindblindness: An Essay on Autism and Theory of Mind (Cambridge, MA: MIT Press, 1995), 12. 


\section{The Narrative Practice Hypothesis}

learning. ${ }^{8}$ Moreover, if speculative uses of folk psychology to determine why someone acted are as unreliable as I have claimed, it seems quite unlikely that the folk psychological framework was originally put in place to provide our ancestors with a powerful predictive-explanatory tool, as it is so often claimed. In this light, we would do well to rethink the role and function of folk psychological 'explanations' in our lives, since their main job is not to generate third-party speculations about what others are likely to think or do or why they acted as they did. This is no way diminishes-indeed it may well enhance-our understanding of the importance of folk psychology and its place in our lives and other practices.

In what follows, I promote the view that our childhood engagement with narratives of certain kinds is the basis of these sophisticated abilities-i.e. it is through such socially scaffolded means that folk psychological skills are normally acquired and fostered. Undeniably, we often use our folk psychological apparatus in speculating about why another may have acted on a particular occasion, but this is at best a peripheral and parasitic use. Our primary understanding and skill in folk psychology derives from and has its primary application in special kinds of second-personal engagements.

It is possible to explain how budding folk psychologists come by a practical grasp of the core folk psychological concepts, as well as the ability to structurally represent how these propositional attitudes normally relate, schematically without postulating any inherited hard-wired 'theory of mind' mechanisms. ${ }^{9}$ A distinct kind of narrative practice, one involving particular kinds of story, engenders folk psychology abilities in the normal populace (of certain cultures, at least). Encounters with narratives about those who act for reasons best explain the origins of folk psychological

8 See D. D. Hutto, 'First Communions: Mimetic Sharing without Theory of Mind', The Shared Mind: Perspectives on Intersubjectivity, J. Zlatev, T. Racine, C. Sinha and E. Itkonen (eds.) (Amsterdam/ Philadelphia: John Benjamins, 2007).

9 In what follows, I will be presupposing that the children in question already have a basic practical grasp of the core concepts of belief and desire. I provide a more detailed account of how they come by these in other writings. I also argue that no existing version of theory-theory or simulation theory can better explain the origin of the core metarepresentational concept of belief in particular. See D. D. Hutto, Folk Psychological Narratives: The Sociocultural Basis of Understanding Reasons (Cambridge, MA: MIT Press, forthcoming). 


\section{Daniel D. Hutto}

abilities, both phylogenetically and ontogenetically. Such stories familiarise us with the forms and norms of folk psychology. This is the core claim of the Narrative Practice Hypothesis (or NPH). The aim of this paper is to introduce this proposal and to make a prima facie case for its acceptance.

\section{What does it take to be a Folk Psychologist?}

Not everyone has what it takes to be a folk psychologist. The birds and the bees don't do it; chimps don't do it. Even little kids don't do it! This should not surprise us. Folk psychology isn't easy-it is a quite sophisticated skill. Mastery of it rests on having met a number of pre-requisites. At the very least, one has to have:

(i) a practical understanding of the propositional attitudes;

(ii) a capacity to represent the objects that these takepropositional contents as specified by that-clauses;

(iii) an understanding of the 'principles' governing the interaction of the attitudes, both with one another and with other key psychological players (such as perception and emotion);

(iv) an ability to apply all of the above sensitively (i.e. adjusting for relevant differences in particular cases by making allowances for a range of variables such as the person's character, circumstances, etc.).

Any interesting explication of folk psychology should not only say what having this rich set of abilities entails, it should also say how it is acquired. On the assumption that these abilities do not come as a 'package deal', I will focus on providing an acquisitional account of (iii) and (iv) in terms of children's engagement in a special kind of narrative practice. This is of interest since, contrary to their advertisements, the rival offerings-theory theory and simulation theory-do not provide any deep understanding of (iii). All the existing theories presuppose some kind of commerce with folk psychological principles, whether this is imagined to take the form of a tacit or explicit theoretical understanding or a practical capacity to manipulate one's own mental states in accord with them (thus, quite literally, embodying them). But presupposing the existence of such abilities is not the same as adequately explaining how they first came to be in place. Ultimately, I think it can be demonstrated that the existing theories do not meet this 


\section{The Narrative Practice Hypothesis}

explanatory demand. ${ }^{10}$ Yet, worse than this, as far as I can see, they do not trouble themselves with giving an account of (iv) at all.

Before getting started, it is worth saying a few words about what distinguishes what it is to have an understanding of desires, beliefs (and even desires and beliefs) from what it is to have an understanding of reasons. Doing so will help us to properly characterise our true quarry. It is empirically well established that children make some propositional attitude ascriptions before they learn to explicate, explain or predict actions in terms of reasons. For example, at around two years of age, children are in secure possession of 'an early intentional understanding of persons having internal goals and wants that differ from person to person'. ${ }^{11}$ The two-year-old's understanding of desires can be rather sophisticated: children understand, for example, how desires relate to emotions and perceptions and what would relevantly and consistently satisfy specific desires-thus they exhibit some fluency with counterfactual thinking of a limited sort.

As impressive as this is, it goes without saying that these abilities do not equate to an understanding of beliefs. Nor would an understanding of desires and beliefs conjunctively equate to an understanding of reasons. These are all logically distinct abilities. We can see the main point at issue if we consider that for a great many coordinating purposes it is often enough to know simply what it is that McX likes or wants. Young children are certainly capable of noting this sort of thing and making good use of it-it is what enables them to make certain low-level, inductively driven predictions about what others are likely to do. But this capacity in itself is quite different from understanding why McX might have acted for a reason. More is needed for that-in particular, the child would have to be able to understand that McX's action issued from a complex 'state of mind', one having a particular kind of implicit structure. Said structure is what one alludes to when one says McX not only likes yoghurt but is eating it for breakfast because he believes it will make him healthy-implying, of course, that good health is also something he seeks.

10 Ibid

11 H. Wellman, A. Phillips, 'Developing Intentional Understandings', Intentions and Intentionality, B. Malle, L. J. Moses and D. A. Baldwin (eds.) (Cambridge, M.A.: MIT Press, 2001), 130; K. Bartsch and H. Wellman, Children Talk About the Mind (New York: Oxford University Press, 1995), chapter 4. 


\section{Daniel D. Hutto}

I mention this because while it is quite unlikely that anyone would confuse the ability to understand and attribute desires with that of being able to understand and attribute beliefs, there is a fairly widespread tendency to conflate the latter sort of ability with a capacity to understand and attribute reasons. This mistake stems from assuming, as is commonly done, that children are already in the possession of the bulk of their theory of mind at the point at which they begin to pass false belief tests. Hence, success on these tests is taken to be the mark of their having acquired the final piece of the 'theory of mind' puzzle. Having mastered the core concept of belief, it is supposed that they have mastered the full set of folk psychological principles.

But if we give due consideration to what false belief tests actually test there is reason to doubt this. In the original version of the false belief test, of which there are now many well-known variants, children were introduced to a puppet, Maxi. ${ }^{12}$ The test was conducted in a room in which a pile of biscuits was the main attraction. In the course of events, Maxi, like the children, observes as the biscuits are put in one of two cupboards. The puppet subsequently leaves the room and during his absence the children watch as an experimenter moves the biscuits into the other cupboard. The question they are asked is: where will Maxi think the biscuits are on his return? For anyone with a sound grasp of the concept of belief, and how perception fixes belief, answering this ought to be straightforward. But, famously, for some-children below a certain age and those with specific impairments-it is not.

Such children have difficulty in ascribing the Maxi-puppet a belief which differs from their own belief about the location of the biscuits. They are unable to ascribe the puppet a false belief, or so it seems. The reason for this is, it has been plausibly suggested, that they are unable to understand that the puppet (or anyone) has a cognitive take on the facts that diverges from their own. Younger children and those with infantile autism cannot simultaneously represent how they take things to stand with the world (from their point of view) and also how things stand from another cognitive vantage point. Thus, in lacking an ability to ascribe false beliefs they demonstrate a lack of an understanding of belief, if we suppose, as we ought, that grasping that concept requires having a metarepresentational ability.

12 H. Wimmer and J. Perner, 'Beliefs about Beliefs: Representation and Constraining Function of Wrong Beliefs in Young Children's Understanding of Deception', Cognition 12, 1983, 103-128. 


\section{The Narrative Practice Hypothesis}

If we stick to the evidence and put aside any prior attachment to theory theory for a moment, it is quite clear that merely having demonstrable metarepresentational abilities-i.e. showing command of the concept of belief-is not equivalent to understanding reasons per se. It is easy to be misled on this score due to the great emphasis that developmental psychologists place on the moment when children begin to pass false belief tasks. As noted above, these are often called 'Theory of Mind' tests but in fact, just as their name suggests, they only test for an explicit understanding of false belief and nothing more. To call them 'Theory of Mind' tests therefore gives a quite erroneous impression, which trades on the assumption that folk psychological abilities simply fall into place automatically once children master the application of the concept of belief. This is simply untrue. Knowing that children manage to pass false-belief tests, reliably enough, at a certain age under very particular experimental conditions, gives no insight into the extent of their understanding of that concept in other contexts. This being the case, such tests certainly do not tell us about the general abilities of children to ascribe or understand reasons, per se.

The myopia associated with conducting and analysing 'false belief tests' has tended to blind researchers to the fact that children's nuanced folk psychological skills only develop securely after ages 4 and 5. Thus, 'Proponents of the dominant theories have been notably quiet about what happens in development after the child's fifth birthday. However research that explores whether 5 -year-olds can use simple false belief knowledge to make inferences about their own and other's perspectives finds that they singularly fail to do so'. ${ }^{13}$ Apparently, it takes some time for them to incorporate their newfound understanding of belief within wider explanatory strategies.

The simple truth, as I said, is that having an understanding of belief is logically distinct from having an understanding of what it is to act for a reason. One can ascribe beliefs using a simple inference rule of the following sort: if McX says (or sincerely asserts) that $\mathrm{P}$ then $\mathrm{McX}$ believes that $\mathrm{P}$ (ceteris paribus). Knowing that McX believes that $\mathrm{P}$ is useful for at least some social coordination purposes-for example, it enables one to predict what else McX might believe. This might be achieved by focusing on

13 J. I. M. Carpendale and C. Lewis, 'Constructing an Understanding of the Mind: The Development of Children's Social Understanding within Social Interaction', Behavioural and Brain Sciences 27, No. 1, 2004, 79-151, 91. 


\section{Daniel D. Hutto}

what McX ought to conclude from thinking that $\mathrm{P}$ (on the assumption that $\mathrm{X}$ observes standard norms of rationality). Very well, but this does not equate to ascribing $\mathrm{X}$ a reason: that would require ascribing to $\mathrm{X}$ a complex state of mind, minimally consisting of a belief/desire pair with interlocking contents. Reasons are not to be confused with isolated thoughts or desires. To think of an action as performed for a reason it is not enough to imagine it as being sponsored by a singular kind of propositional attitude; one must also ascribe other kinds of attitudes which act as relevant and necessary partners in motivational crime.

This is not always evident given the way reason explanations are often presented. As noted before, they are generally truncated. But what I have sought to emphasize is that having a discrete understanding of the core propositional attitudes-belief and desire-is only a necessary but not a sufficient condition for being a practising folk psychologist. Having issued that reminder, we can now turn to the main event.

\section{Acquiring Folk Psychology in ontogeny}

How, during childhood, do we come by our everyday folk psychological skills and understanding? This familiar achievement rests on a complex series of foundations-i.e. children must already have a number of more basic imaginative abilities and interpersonal skills in order to learn how to make sense of actions in terms of reasons successfully. Long before they are able to do this, they are at home in navigating their social worlds in embodied and imaginative ways: they get by in the earliest stages of their interpersonal careers without ever attributing desires, beliefs, or reasons to anyone. In time, they get a practical grasp on the different kinds of propositional attitudes-learning about each in discrete stages, as their command of language and its syntactic constructions grows. I have elsewhere argued at length that there is good reason to think that children come into the possession of all the pieces needed for playing the understanding-action-in-terms-of-reasons game before they can actually play it. ${ }^{14}$ What they are missing in their early years, if I am right, is not the components needed to play this game: they lack knowledge of the basic rules for doing so.

For, as noted in the previous section, proficiency in making isolated propositional attitude ascriptions-attributing certain

14 Hutto, ibid. 


\section{The Narrative Practice Hypothesis}

goals, desires, thoughts and beliefs-is not the same as knowing how these combine to become reasons. This stronger condition must be satisfied if one is to be a folk psychologist. This requires mastery of the norms governing the interplay between these attitudes. What children are missing, even upon acquiring a practical grasp of the concept of belief, is not therefore another ingredient needed for baking the folk psychological cake-rather it is the instructions for mixing all the ingredients properly to make many such cakes. But if the instructions for this are not built into their minds, how exactly might they be acquired?

The Narrative Practice Hypothesis (NPH) claims that children normally achieve this understanding by engaging in story-tellling practices, with the support of others. The stories about those who act for reasons-i.e. folk psychological narratives-are the foci of this practice. Stories of this special kind provide the crucial training set needed for understanding reasons. They do this by serving as exemplars, having precisely the right features to foster an understanding of the forms and norms of folk psychology. By participating in this kind of narrative practice children become familiar with the way the core propositional attitudes, minimally belief and desire, behave with respect to each other and their familiar partners: emotions, perceptions, etc. More than this, in such stories a person's reasons are shown in situ; against appropriate backdrops and settings. For example, children learn how a person's reasons can be influenced by such things as their character, history, current circumstances and larger projects.

It is because they have just these features that folk psychological narratives as well as the fact that they are complex objects of mutual attention can play this crucial role. Most children are not only repeatedly exposed to such stories, but normally this occurs in a very rich setting, with engaged participants on both sides. It is helpful to remind ourselves of this, lest we are swayed by misguided poverty of the stimulus arguments into believing that the postulation of inherited 'theory of mind' devices is unavoidable. ${ }^{15}$

15 Several philosophers have suggested that a Poverty of the Stimulus Argument concerning the acquisition of folk psychology could be developed that would parallel the version Chomsky developed in support of his claims about the existence of innate linguistic knowledge, see P. Carruthers, 'Moderately Massive Modularity', Minds and Persons, A. O'Hear (ed.) (Cambridge: Cambridge University Press, 2003), 71; G. Botterill and P. Carruthers, The Philosophy of Psychology (Cambridge: 


\section{Daniel D. Hutto}

The assumption behind that line of thought is that the acquisition of folk psychology 'poses the same degree of a learnability problem as does the rapid acquisition of linguistic skills, which appears to be similarly rapid, universal and without sufficient stimulus from the environment'. ${ }^{16}$ Yet, with respect to folk psychology, the argument has not been spelt out in any detail. Any prima facie plausibility it has derives simply from the idea that children could not possibly fashion the rich product that is folk psychology by applying their general reasoning abilities in response to impoverished stimuli. But this idea is only remotely credible if we have in a mind a quite implausible picture of how children might become aquainted with the rules of folk psychology in the first place; to be sure they do not encounter these as set of serial announcements issued by their parents. And, of course, acquiring an understanding of folk psychology by means of participating in narrative practices, with the support of others, is nothing like being read off a set of explicit principles or rules to be committed to memory. It is only if one has this second model in mind that it is tempting to agree with Goldman that few children 'have mothers who utter [folk psychological] platitudes' ${ }^{17}$

Engaging with narratives, and those of the folk psychological variety in particular, is anything but a passive affair: a wide range of emotive and imaginative abilities are typically brought into play. For example, even to appreciate such stories children must be initially capable, at least to some degree, of imaginative identification with the characters of the story. And not only will they be exercising their recreative imaginations in this way, they will also be responding emotively, just as they do in basic social engagements, such as joint attention. In this respect, 'conversations about written and oral stories are natural extensions of children's earlier

Cambridge University Press, 1999), 52-3; J. A. Fodor, Psychosemantics (Cambridge, MA: MIT Press, 1987), 133; see also K. Sterelny, Thought in a Hostile World (Oxford: Blackwell, 2003), 214).

16 S. Mithen, 'Mind, Brain and Material Culture: An Archaeological Perspective', Evolution and the Modern Mind: Modularity, Language and Meta-Cognition, P. Carruthers and A. Chamberlain (eds.) (Cambridge: Cambridge University Press, 2000), 490.

17 A. I. Goldman, 'In Defense of the Simulation Theory', Mind and Language 7, 1992, 104-119, 107. 


\section{The Narrative Practice Hypothesis}

experiences with the sharing of event structures' ${ }^{18}$ It is therefore of no surprise that young children's first narrative encounters are with picture books that only depict objects, emotions and actions-but not reasons for actions. They slowly graduate to stories that concentrate on the kinds of complex psychological attitudes of characters; those who find themselves embedded in increasingly complex social dramas.

But it is not just the content of such stories that matters. Sophisticated demands are also placed on children in the course of hearing, discussing and learning from them. Thus it is normal for children to be directed by caregivers to attend to the thoughts, desires, and feelings of story characters and these are often explained to and contextualised for them. Throughout these interactions children will be calling on a prior bit limited mastery of mentalistic terms and concepts. Crucially, however, these are not simply mentioned in story-telling practices, rather children are prompted at crucial points to offer their own explanations; they are invited to apply, demonstrate and extend their prior understanding. For example, while reading stories it is typical for adults to press for answers to questions such as: 'Why do you think $\mathrm{X}$ did that?'. Moreover, those who tell stories to young children generally go beyond the strict text-using voices, enacting character responses, and providing details that reveal or hint at the motivations and rationales of characters. Such exchanges are a mix of dramatic re-enactment, contextualisation, and exposure to further examples, all of which prompt further requests from listeners and opportunities for correction from the story-tellers. ${ }^{19}$

In these guided encounters with such stories children come to see the relations that hold between the various psychological attitudes-crucially, but not exclusively, the focus is on beliefs and desires. This is important because, as stressed above, not only must children have an understanding of the core propositional attitudes, they must also learn how these inter-relate. Thus the way beliefs and desires conspire to motivate actions-which, in abstracto, we

18 N. R. Guajardo, A. Watson, 'Narrative Discourse and Theory of Mind Development', The Fournal of Genetic Psychology 163, 2002, $305-325,307$.

19 Also, this kind of interpersonal activity occurs at the right point in the developmental schedule of most children, making it plausible that it might form the basis of their folk psychological training. People-focused conversations happen early on and story-telling activities of the relevant sort are usually well under way by the time children reach the ages of three and four. 


\section{Daniel D. Hutto}

might think of as the folk psychological schema-is a constant feature of these narratives. But this requires knowing not only how they inter-relate with one another, but also how they do so with other standard players in psychological dramas. In sum, these comprise what we might think of as the 'core principles' of intentional psychology.

According to the NPH these 'princples' are revealed to children not as a series of rules but by showing them in action, through narratives, in their normal contexts of operation. In this way, narratives not only show which features are constant to folk psychological explanation but also, importantly, what can vary in such accounts-such as the particulars of what a person believes and desires, how these attitudes can change over time and why, and also how character, history, and other commitments might impinge on why a person acts as they do. All of this is put on show. In this way children learn which kinds of factors must be taken into account and adjusted for when it comes to making sense of the stories that others tell about the reasons why they acted, as well as learning what needs mentioning when providing their own. It is in this way and in this sense that children acquire an understanding of the core structure of folk psychology, its governing norms, and guidance on its practical application. This is not a process through which children distil a set of general rules.

To understand the NPH aright, two senses of 'narrative' must be distinguished-i.e. the narratives which are the third-personal objects of focus, and the narratives through which these are presented and shared-i.e. the acts of narration that constitute the second-personal story-tellings. As an object, a narrative-the story itself-might be spontaneous production, an autobiographical account, a bit of gossip, or an established cultural artefact. Many of the latter are texts of which there may be multiple versions-such as Perrault's 'Little Red Riding Hood' or its Grimm Brothers variant 'Little Red Cap'. Indeed, this is one of the best known folk psychological narratives:

Little Red Riding Hood learns from the woodcutter that her grandmother is sick. She wants to make her grandmother feel better [she is a nice, caring child], and she thinks that a basket of treats will help, so she brings such a basket through the woods to her grandmother's house [beliefs and desires lead to actions]. When she arrives there, she sees the wolf in her grandmother's bed, but she falsely believes that the wolf is her grandmother [appearances can be deceiving]. When she realizes it is a wolf, she 


\section{The Narrative Practice Hypothesis}

is frightened and runs away, because she knows wolves can hurt people. The wolf, who indeed wants to eat her, leaps out of the bed and runs after her trying to catch her. ${ }^{20}$

Tales of this sort are legion. This is not, I take it, in doubt, although as yet I have no precise data on how many of these children encounter in the normal course of their development; I leave it to the reader to speculate about this. What matters is that they are the best means of revealing how propositional attitudes work together in motivating actions and indicating which other factors might make a difference. Given their content, they have precisely the right properties for this work.

Well crafted cultural artefacts, like the familiar fairy tale cited above, are a secure medium of achieving this. They are amongst the earliest forms of published fiction, typically deriving from orally preserved folk tales. Yet any story that describes reasons for action, even those related through casual conversations, has the potential to do so, even if they are not as well-structured as the canonical texts used in much pre-school story-telling. With this in mind it is diffcult to imagine how to motivate a poverty of the stimulus argument in this domain, since these narratives are regularly traded in run-of-the-mill conversations. Indeed, it is through listening to and participating in conversations about people and why they act that children first hear propositional attitudes being discussed and described, and it is likely that it is through this route that they learn about the kind of objects these take-complex linguistic constructions embedded in that-clauses. It is stories featuring people and their reasons for acting-however these are conveyed - that familiarise children with the folk psychological framework and practical knowledge of how to apply it.

Children are not simply learning generalisations-i.e. mere soft laws-about what people typically do; they are learning how to apply the folk psychological framework.

Although I previously emphasised the imaginative identification and emotional responding that characterises engagement in narrative practice, it is also worth highlighting how straightforward it would be for children to pick up the structural template of means-end reasoning through such encounters. It is into this framework that particular propositional attitudes, beliefs and desires, are inserted, like arguments in place of variables-based on

20 A. Lillard, 'Other Folk's Theories of Mind and Behaviour', Psychological Science 8, 1997, 268-274, 268, emphases mine. 


\section{Daniel D. Hutto}

what we learn (or are told) about why someone acted (or why we speculate they may have acted). Similarity-based connectionistnon-sentential-accounts of cognitive processing that trade in stereotypes, prototypes and exemplars are well placed to explain the working of the underlying mechanisms which might make this possible. Picking all this up from narrative encounters would be easy work for our pattern-completing, form-finding brains.

A major virtue of the NPH is that it does not need to characterise this aspect of the learning process as one of 'scaling up' or 'bootstrapping'; to do so is rightly to be accused of hand waving. ${ }^{21}$ For in this case the training 'input' is identical to learned 'output': the structures to be acquired are clearly detectable in the exemplars-the folk psychological narratives-themselves (this can be seen by replacing the italicised mentalistic verbs in the 'Red Riding Hood' excerpt with a series of neutral symbols). And it is well known that connectionist networks can 'learn' both lexical categories (e.g. nouns, verbs) and grammatical structures (e.g. agreement and dependence of embedded clauses) using their humble resources. In summarising the evidence on this score, Prinz remarks that 'Elman shows that a dumb pattern detector can pick up on structural relations'. ${ }^{22}$ Note too that the folk psychological template is a much simpler kind of structure than even the most basic of syntactic patterns. All that is required in order to make the NPH credible on this score is the assumption that the child's world is adequately populated with folk psychological narratives and that they have enough opportunities to engage with them. This seems to be the case, in most cultures.

It should also be recognised that although this framework is derived from ambient stories, and is not part of a built-in theory, this in no way detracts from the power and depth it affords in making sense of others in particular cases. Its source does not affect its capacity to 'go beyond the evidence' when explaining and predicting what actors are likely to do in 'novel' cases (although, as stressed, such third-personal uses are not a reliable method of

21 A. Gopnik, The Theory Theory as an Alternative to the Innateness Hypothesis, Chomsky and His Critics, L. M. Antony and N. Hornstein (eds.), 2003, 238-254, 243.

22 J. Prinz, Furnishing the Mind: Concepts and Their Perceptual Basis (Cambridge, MA: MIT Press, 2002), 206. 


\section{The Narrative Practice Hypothesis}

discovering another's reasons for acting). ${ }^{23}$ Folk psychology exhibits precisely the sorts of features that led philsosophers, such as Lewis, to mark it out as being theory-like-i.e. it has characteristics that makes the 'theory theory' a compelling hypothesis. ${ }^{24}$ Nevertheless, despite having a coherent framework at its core, folk psychology is not, in fact, theoretical in its origins or principal applications.

It is worth saying a bit more about this. Many philosophers who are attracted to theory theory are of the view that the content of theoretical concepts is determined by the role they play in a network of principles-principles which, when working in unison, enable the prediction and explanation of action. It is also commonly held that the 'meanings' of mental predicates, those which form the basis of such principles, are fixed in the same way; i.e. terms such as belief, desire and hope are defined by the way they systematically interrelate with one another and with other terms.

However, the claim that the meaning of mental predicates depends wholly on their lawful relations is apparently undermined by the fact that children develop a practical understanding of the different propositional attitudes at distinct stages in their early careers. Thus they have a grasp of the concept of desire, quite independently of and prior to having an understanding of belief. And an understanding of both of these attitudes appears to precede an understanding of the roles they play in making sense of a person's reasons for action. At best, then, it seems that children significantly extend their understanding of the core propositional attitudes when they learn how these cooperate with one another (and others of their ilk) in the context of reason explanations. It is not that the later ability constitutes their understanding of mental predicates. Nevertheless, it is getting to grips with the roles played by the attitudes in this context that is, minimally, what is required to be capable of understanding what it is to act for a reason.

23 The capacity to go beyond the evidence has been singled out as 'the most important evolutionary benefit of developing theorising abilities' (A. Gopnik and A. N. Meltzoff, Words, Thoughts, and Theories (Cambridge, M.A.: MIT Press, 1996), 37). Good theories run deep: their power to anticipate, explain and control stems from their tapping into the world of the unseen and the abstract.

24 See D. Lewis, 'How to Define Theoretical Terms', Fournal of Philosophy 67, 1970, 427-446; D. Lewis 'Psychophysical and Theoretical Identifications', Australasian Fournal of Philosophy 50, 1978, 249-258. 


\section{Daniel D. Hutto}

To be a practising folk psychlogist rests on having an understanding of the roles that mentalistic concepts play in a framework of this sort. Some have concluded, because of this, that the framework in question is a theoretical one and mental predicates thus have a theoretical status. But that is a mistake. It may be an essential feature of all theories that they have complex network structures-and it may even be that the meanings of theoretical terms are determined entirely by the roles they play within such networks (well, maybe). All of this could be true without it being the case that folk psychology is a theory. Clearly, the mere fact that something has a framework structure does not entail that it is a theory or that the meaning of its concepts is holistically constituted. Ordinary games, such as cricket or chess, have rules, but these activities are not theoretically but conventionally grounded; they are well-established, regulated social practices. Folk psychology, too, has a framework structure, but it is neither a game nor a theory.

So, it looks like we should agree with holistically minded theory-theorists only up to a point: in order to understand what it is to act for a reason we must understand the roles played by the mental predicates. But this gives us absolutely no reason to think of such concepts as theoretical constructs-similar to 'electrons', 'atoms', or 'gravity'. To be sure, to understand the distinct roles that such concepts play in folk psychology requires having an understanding of their place in a network of possibilities. But, at most, this means that, in this context, mentalistic terms may be similar in this one respect to certain theoretical terms (on the disputable assumption that this is the best way to make sense of the meaning of theoretical constructs). Folk psychology need be like a theory in no other interesting aspect, neither in its origins nor its primary applications.

For all these reasons, using the label 'theory of mind' as a byword for folk psychological practice is highly misleading. The practice should be shunned in light of the bad effects it has had (and continues to have) on the imaginations of many philosophers, psychologists and others working in this topic.

\section{Norms of practical applicability}

Successful application of folk psychology involves more than merely getting to grips with its core structure, it requires development of refined skill. One must be able to use it, sensitively, 


\section{The Narrative Practice Hypothesis}

occasion by occasion. Encounters with folk psychological narratives help foster this practical ability as well. For, although the structure of intentional psychology is a constant in all folk psychological narratives, they vary in other aspects. Through them children also learn that many non-mentalistic factors are pertinent to why someone has acted or might act. For example, they learn that what a person believes or desires matters to the actions they take but also how their character, unique history and circumstances might affect their motivational set. These are the sorts of features, inter alia, that differ from story to story, within a single story over time, and often from protagonist to protagonist within the same story. They are prominent in nearly all interesting stories even if only in the background. Knowing how to make relevant adjustments to accommodate just such factors is necessary for the skilled application of folk psychology. The simplest person-narratives engender this kind of practical knowledge by introducing children to distinct characters and their specific background beliefs and desires, particular agendas, unique histories, personality traits and so on. Although the stories in which they figure are at first quite simple, they become more sophisticated over time.

The main point, yet again, is that these stories have precisely the right properties for familiarising children, not only with the core mentalistic framework, but also with the rudimentary norms governing its practical application. By putting examples of people acting for reasons on display, they show both how the items in the mentalistic toolkit can be used together to understand reasons in general, as it were, but also how and when these tools might be used-i.e. what to adjust for-in specific cases. They not only teach children this but they also give some hints about how to make the relevant adjustments (e.g. a character with suspicious tendencies is likely to form certain beliefs in such and such a situation, etc.). Encounters with such stories look ideally suited to provide children with the requisite specialised know-how-i.e. to teach them how to apply folk psychology, with sensitivity, in everyday contexts.

The NPH therefore has the potential to explain something its rivals do not; insight into how we might acquire our workaday skills in wielding folk psychology. This matters, for if an effective use of folk psychology requires getting to grips with the sorts of factors mentioned above, there is little to recommend the thought that such 'practical worries' can be shunted to one side and dismissed when it comes to understanding FP abilities. Surprisingly, this is the standard strategy. Thus, it is widely supposed that questions about day-to-day 'application' can be relegated to the sideline and dealt 


\section{Daniel D. Hutto}

with by a liberal invocation of ceteris paribus clauses. Consequently, although everyone acknowledges that there are many factorspsychological and non-psychological-that are relevant to any particular attempt to make sense of an action in terms of reasons, our ability to cope with these in practice is treated as if it is outside the scope of folk psychology per se. The mainstream offerings, theory theory and simulation theory, are conspicuously silent on the question of what grounds this aspect of folk psychological practice. To my eye, this is a serious lacuna.

Most theorists do not accept that there is a need to give an account of such practical knowledge because they imagine, quite wrongly in my opinion, that 'folk psychology' just is the name of a theory or procedure; one which can be understood quite independently from its practical application. I take the opposite view: although folk psychology has a core framework-which can be abstractly described as a set of principles-it is first and foremost a practical enterprise. Its business just is the application of a special narrative framework in specific cases of making sense of actions. Any theory of folk psychology that fails to recognise and to account for this will ultimately fail to satisfy. And this, I fear, is true of all existing accounts.

Take theory theory as an example. Here the sole focus is on explaining the nature of the basic rules of folk psychologyunderstood in vacuo-those which define its core mentalistic framework. Little attention is given to the question of how children learn to apply these rules in practice. Rather it is often supposed that we somehow rely on a tacit understanding of 'idealised rational agents' when making mentalistic predictions and explanations. ${ }^{25}$ This is, so it is claimed, a necessary condition for getting any mentalistic attribution off the ground. Thus, if I know that McX is thirsty for a glass of water, and I know that he believes he could get one by going downstairs to the refrigerator I will probably predict that he will do just this (all else being equal and assuming he has the right sort of background beliefs and desires, etc.). But I will only expect this of McX if I think he will behave as any 'rational agent' would. For if McX is irrational, interpreting or predicting his behaviour in terms of his reasons is a non-starter.

25 Cf. D. C. Dennett, Brainstorms (Cambridge, MA: MIT Press, 1985), 16-22; D. C. Dennett, The Intentional Stance (Cambridge, MA: MIT Press, 1987), chapter 4; S. Stich, The Fragmentation of Reason (Cambridge, MA: MIT Press, 1990), chapter 2, chapter 3. 


\section{The Narrative Practice Hypothesis}

In one sense this is surely right. But knowing this is hardly sufficient for being a practising folk psychologist; our everyday skill involves much, much more than knowing in some thin, attenuated sense that a person has acted or might act thus and so because they have a certain belief/desire pairing and that they are not irrational. Alone, knowing all of this would not be much help in making a person's actions intelligible. In those interesting cases in which we might need to make sense of McX's action we would need a much thicker description not just of his psychological set, but of his character, his history and his circumstances. In effect, we need to know his particular story.

Sustained experience with folk psychological narratives primes us for this richer practical understanding by giving us an initial sense of: which kinds of background factors can matter, why they do so, and how they do so in particular cases. Stories can do this because they are not bare descriptions of current beliefs and desires of idealised rational agents-they are snapshots of the adventures of situated persons, presented in the kinds of settings in which all of the important factors needed for understanding reasons are described; those that are relevant to making sense of what is done and why.

The various personae dramatis in such tales, even the not very interesting ones, each have their own unique psychological profile consisting not only of occurrent psychological attitudes but also habitual tendencies or other personality traits (which may conflict in various ways). They depict reasoners to be sure, but not ideal ones. The principal players in narratives have substantial attributes; these may make them admirable, pitiful or deeply or tragically flawed. It is the knowledge that people too have such attributeslearning what to watch out for and how to recognise these-that, in large part, fuels the activity of making sense of their actions (and indeed our own). This is at a far remove from making generalisations about what we can expect that any rational 'someone' might do or might have done in specified circumstances.

Once again, this works because story characters, like their real-life counterparts, do not pursue their projects in a vacuum. Often their reasons for taking a particular course of action are influenced by their character, larger projects, past choices, existing commitments, ruling passions or unique circumstances and history. My claim is that our ability to make sense of intentional action in practice-and our proficiency at doing so-rests on our knowing in general which details might be relevant and knowing how and when to make the appropriate adjustments in particular cases. Folk 


\section{Daniel D. Hutto}

psychological narratives are uniquely well-suited to foster this kind of understanding because they provide examples of people acting for reasons in appropriately rich settings.

Admittedly, a full and properly nuanced awareness of what is involved in acting for a reason requires acquaintance with narratives of a much more sophisticated kind than those that feature in pre-school dialogues and simple fairy tales. There is much more on offer in adult conversations and grander literary offerings. The characters that populate children's stories would struggle even to pass muster as, what E.M. Foster called, 'flat characters'; those who 'can be summed up in a single sentence'. ${ }^{26}$ Typically, storybook characters and the situations in which they find themselves are not very complex. Little Red Riding Hood is no Madame Bovary, to be sure. But this does not change the fact that such early narrative encounters supply the basics needed for acquiring a first understanding of reasons. This is folk psychology 101, after all, not grad school.

I opened this paper by saying that it is a test of adequacy for any good theory of folk psychology that it should be capable of explaining (at least potentially) not just how we acquire an understanding of the core mentalistic framework but also how we acquire our normal capacity to apply it sensitively in practice. This is integral to what we most want to understand about the distinctive but everyday phenomenon of making sense of intentional actions; it is not an optional extra. The importance of this can be best seen if one considers that it is possible to learn about the core folk psychological principles without knowing how or when to apply them (or at least not with the same fluency that ordinary practitioners of intentional psychology exhibit). One could learn how the core mentalistic predicates relate to one another in conceptual space without knowing, for example, how they function in a richer setting i.e. without having any idea of how or when they should be ascribed, as might happen if one learned such principles by means other than by engaging with folk psychological narratives in early childhood. Pretty clearly, on its own such an understanding would be of limited value.

Let me be clear about one other aspect of the central claim of the $\mathrm{NPH}$. Although exposure to person-narratives is the normal route for learning the forms and norms of folk psychology, it is possible to achieve this (or something approximating to it) by other means. Apparently, it is possible to learn the basic rules of folk psychology

26 Goldie, ibid, p. 3. 


\section{The Narrative Practice Hypothesis}

off by heart, as some individuals, initially diagnosed with infantile autism, have seemingly managed to do. The process is described as a purely 'logical one', using observation to fashion a set of useable generalizations that are then committed to memory, as are the principles for their application. On this basis, autistic individuals have been described as being able to 'compute' and 'calculate' what others are thinking and feeling based on available evidence, as if they were using a set of algorithms. ${ }^{27}$ This is achieved in later life, perhaps thanks to their strong general intelligence and powerful rote memories, in order to compensate for their lack of insight into the reasons why others act. This is the most likely explanation of how such individuals eventually become capable of passing false belief tasks.

Picking up the relevant folk psychology principles and rules for their application as sets of explicit regulations is quite unlike the training I suggest is imparted through storytelling practice. And the effects of this alternative kind of training regime are transparent. Those who acquire their folk psychology skills in this way remain quite awkward in their dealings with others; they never fully develop a capacity to make sense of actions in the easy and familiar way that most of us do. ${ }^{28}$ The phenomenological differences are also salient. ${ }^{29}$ For example, Temple Grandin, an autistic individual who has, by her own account, succeeded in fashioning rules for understanding others in this way still 'describes herself as like an anthropologist on Mars'.30

Of course such feelings of estrangement have deeper roots, but the point is that these persist even after autistic individuals learn to master false belief tasks. This suggests that they never quite achieve the kind of understanding of others that is the norm for most

27 See D. Bowler, “'Theory of Mind' in Asperger's Syndrome', Fournal of Child Psychology and Psychiatry, 33, 1992, 877-893; S. Gallagher, 'Understanding Interpersonal Problems in Autism: Interaction Theory as an Alternative to Theory of Mind', Philosophy, Psychiatry, Psychology 11, 2004, 199-217.

28 See R. Eisenmajer and M. Prior, 'Cognitive Linguistics Correlates of 'Theory of Mind' Ability in Autistic Children', British Fournal of Developmental Psychology 9, 1991, 351-364; F. Happé, 'The Role of Age and Verbal Ability in the Theory of Mind Task Performance of Subjects with Autism', Child Development, 66, 1995, 843-855.

29 D. Zahavi and J. Parnas, 'Conceptual Problems in Infantile Autism Research', Fournal of Consciousness Studies 10, 2003, 53-71.

30 J. Kennett, 'Autism, Empathy and Moral Agency', The Philosophical Quarterly 52, 2002, 340-357. 


\section{Daniel D. Hutto}

people. If nothing else, consideration of such cases should discourage the tendency to think that folk psychology is nothing more than the name for a theory or set of rules, as opposed to a special sort of rule-based know how. This is a salient reminder that our true explanandum, our real quarry, is a highly nuanced and skilled practice-albeit one that makes use of the core mentalistic framework.

Extracting this schema and becoming familiar with the norms for its application through experience with a certain class of discursive narratives is the culminating, non-negotiable requirement for a basic mastery of our everyday folk psychology abilities. Engaging in the relevant kind of story-telling practice is the normal route through which this practical knowledge and understanding is procured.

\section{The myth of Jones (remixed)}

But if this is right, what should we say about the ultimate origins of our folk psychological abilities? Here I take a leaf out of Sellars' book; both in making clear the limit of my ambitions while also adapting the central feature of his basic proposal. Sellars concocted a famous myth-which he explicitly identifies as a piece of anthropological science fiction-in order to show the conditions under which our Rylean ancestors-who would have been wedded to a kind of methodological behaviorism-might have graduated to a more non-observationally based understanding of 'inner episodes of thought'. This is accomplished, Sellars imagines, by a genius, whom he calls Jones, who came amongst them. The great Jonesean insight was to model the inner thoughts of his compatriots on their overt speech acts and by doing so he developed a new means of explaining their intelligent acts, even when these were unaccompanied by any outward verbal behaviour. ${ }^{31}$

In the very same way, we can imagine that reasons-minimally, logically interlaced belief/desire pairings-might have been originally modelled on overt narrations. These would have been temporally extended, public speech acts that detailed, at bare minimum, the episodes of practical reasoning that detailed one's rationale for acting. They would have provided accounts, for example, of plans constructed and acted upon on the basis of

31 See W. Sellars, Empiricism and the Philosophy of Mind (Cambridge, Mass.: Harvard University Press, 1956/1997), 102-107. 


\section{The Narrative Practice Hypothesis}

manipulating propositional beliefs and desires in appropriate ways. We can suppose then that just like the overt speech acts that served as Jones' original inspiration, these more complex narratives would have been supplied by the authors of these activities, in the first instance. Of course, this assumes that these narrators had command of a logically complex natural language; since they would have had to be at home with the practice of making plans based on bouts of practical reasoning involving propositional attitudes, expressing themselves in this way, and so on.

What matters is that in such story-tellings one's reasons for acting would have been put on exhibit for all to see. Presumably, such narratives would have been public spectacles, taking the form of complex third-personal representations for the benefit of a shared audience-i.e. they would have been issued in secondpersonal contexts. In short, we can imagine that such public narrations would have provided the model for what it is to act for a 'reason' in just the same way that less complex utterances served Jones in developing his understanding of inner episodes of thought. ${ }^{32}$

The importance of this Sellarsian myth is that it serves to remind us of the primacy of second-person, public practices in establishing our understanding of ourselves and others as persons who act for reasons. Given this ambition it may seem odd that I have borrowed from Sellars. After all, he is frequently presented as an arch theory-theorist, indeed possibly even the progenitor of the kind. Surely, his myth is better suited to support the idea that, at its root, folk psychology is a model used for third-personal explanation. Indeed, it is common to hear that 'Early formulations of the notion of folk psychology stressed the idea that folk psychology is an explanatory theory. This is much to the fore, for example, in Sellars'

32 Like Sellars, I do not want to elevate this suggestion beyond the status of a myth in the sense that I make no claims about exactly how this might have come about. But if we assume that the basic logic of this story is right, it would seem that the practice of folk psychology is likely to have emerged relatively late in the pre-history of our species. Even though we do not know exactly when sophisticated linguistic abilities and the relevant discursive practices might have emerged, it is a good bet that, 'symbolic language, with the central function of narrative making, emerged only with Homo sapiens about thirty-five thousand years ago and was accompanied by a rapid acceleration of cultural growth'. See K. Nelson, 'Narrative and the Emergence of a Consciousness of Self', Narrative and Consciousness, G. D. Fireman, T. E. J. McVay and O. Flanagan (eds.) (Oxford: Oxford University Press, 2003), 24. 


\section{Daniel D. Hutto}

influential mythical account of how folk psychology might have emerged'. ${ }^{33}$ However, one really should not read too much into Sellars' talk of a Jones having created a 'theory', especially given the source of his model. Certainly, the way the story plays out, Jones uses his model in order to effect third-personal speculations. And this is surely a possible use of folk psychology; though it is-to be sure-not a very reliable one. Even so, this gives us no reason to suppose that supporting such third-personal speculation is or was the primary use of the folk psychological framework.

Even so, it might be objected, Sellars emphasizes the fact that the way in which Jones constructs his model of non-observational 'inner episodes of thought' parallels the way in which theoretical posits are, in general, constructed. But consider that he only ever claimed that his 'story helps us to understand that concepts pertaining to such inner episodes are primarily and essentially intersubjective, as intersubjective as the concept of a positron, and that the reporting role of these concepts-the fact that each of us has a privileged access to his thoughts-constitutes a dimension of the use of these concepts which is built on and presupposes this intersubjective status'. ${ }^{34}$ I too have been at pains to stress this intersubjective, indeed socio-cultural, basis of our understanding of reasons, but this hardly commits me-or anyone who follows suit- to the idea that that understanding is theory-based, theory-like or formed as a product of explicit theorizing.

To see this it may help if one observes that in my new version of the Sellarsian myth, my Jones, like the orginal one, is not really a creative mastermind; he is more an attentive listener. He pays close attention to the stories of his fellow practical reasoners. For it is by hearing these often enough (or, more plausibly, by actively participating in conversations about these) that he becomes acquainted with a basic understanding of what it is to act for a reason. This would have supplied him with a framework that he can apply again and again when making sense of actions performed for reasons. My proposal is that the story is much the same with us.

33 Bermúdez, ibid., 47, emphasis added.

34 Sellars., ibid., 107, emphasis added. 